\title{
LA ESCRITURA COLONIAL: AGENCIAMIENTO DE CUERPOS Y LENGUAS NO TIPOGRÁFICAS
}

COLONIAL WRITING: AGENCING OF BODIES AND NON-TYPOGRAPHIC LANGUAGES

\author{
Eugenia Ortiz Gambetta \\ ORCID 0000-0001-5316-1615 \\ Universidad Católica Argentina \\ Buenos Aires, Argentina
}

\begin{abstract}
Resumen
La escritura europea irrumpe en el espacio americano durante la Conquista. Diversos testimonios revelan esas dinámicas de jerarquización y dominación de voces y lenguas no tipográficas. La propuesta de este artículo es recontextualizar el proceso de agenciamiento de saberes y cuerpos a partir de la consideración de presupuestos teológicos y epistemológicos sobre la verdad y la preeminencia del Logos, y cómo se confrontó especialmente la voz hecha cuerpo en los cantos y bailes de los nativos americanos como fenómenos esquivos de este proceso.
\end{abstract}

Palabras claves: Escritura, Lenguas no tipográficas, Conquista, Cuerpo, Textos. coloniales

\section{Resumo}

A escrita europeia invade o espaço americano durante a Conquista. Diversos testemunhos revelam essas dinâmicas de hierarquização e dominação de vozes e línguas ágrafas. A proposta deste artigo é recontextualizar o processo de agenciamento de saberes e corpos a partir da consideração de pressupostos teológicos e epistemológicos sobre a verdade e a preeminência do Logos; e como foi confrontada especialmente a voz feita corpo nos cantos e danças dos nativos americanos, considerados fenômenos esquivos para este processo.

Palavras-chave: Escrevendo, Línguas não tipográficas, Conquista, Corpo, Textos coloniais.

\begin{abstract}
European writing burst into the Latin American space during the Conquest. Various testimonies reveal these dynamics of hierarchisation and domination of voices and non-typographic languages. This article seeks to re-contextualize the agencing of knowledge and bodies based on the consideration of theological and epistemological presuppositions about truth and the preeminence of Logos, and how the voice turned body in the songs and dances of the Native Americans, as elusive phenomena in this process, were regarded.
\end{abstract}

Keywords: Writing, Nontypographical Languages, Conquest, Body, Colonial Texts. 
Lo único que uno hace es agenciar signos y cuerpos como piezas heterogéneas de una misma máquina.

Deleuze y Parnet, Diálogos.

La lengua del imperio y las culturas no-tipográficas americanas

El acceso a las culturas no-tipográficas americanas sólo ha sido posible a través de la cultura alfabética europea: testimonios escritos o interpretaciones de dispositivos de memoria han sido mediados por toda forma de traducción. La ilusión de acceder a la "autenticidad" de las culturas indígenas, al decir de Gruzinski (2016: 10), debe dejarse de lado para considerar que la irrupción de la cultura alfabética acompañó el largo proceso de occidentalización de América. A partir de este punto de partida, se podrían marcar varios hitos en relación con la aparición de la letra asociado a la norma y la autoridad, fenómeno que necesariamente estuvo atravesado por visiones de mundo y múltiples interpretaciones sucesivas y simultáneas (11-13). Las culturas no-tipográficas sufrieron el "mal de archivo", al decir de Derrida (1997), y en muy pocos casos lograron acceder al milagro de su supervivencia. Una recuperación de ese archivo debería dar cuenta de los registros de los pueblos americanos antes del contacto con el europeo, pero lo que se puede reconstruir son casos y suposiciones a partir de la lectura de soportes de toda índole: mapas, jeroglíficos, inscripciones en piedra, en vuh y amoxli, en tejidos y en cuerdas. A partir de éstos, y de los textos coloniales, se puede lograr una suerte de decodificación de las culturas preexistentes en un terreno extensísimo, que de todos modos ha tenido un denominador común de alta complejidad. La información reinterpretada por individuos originados en esos contextos (los amanuenses náhuatl del Códice Florentino, el trabajo de Guamán Poma de Ayala, las crónicas mestizas, entre otros) han llegado a nosotros con las transformaciones propias de este fenómeno.

Un recorrido de la irrupción de la cultura escrita en América debe tener en cuenta también el culto al Verbo, la exegética católica, la doctrina y las concepciones filosóficas y teológicas que acompañaron este proceso. Esto, por ejemplo, se podría hacer a partir del estudio de la lingüística misionera, disciplina en la que se vienen aportando nuevos enfoques y perspectivas pedagógicas, catequéticas y filológicas (SUÁREZ ROCA, 1994; HOVDHAUGEN, 1996, ZIMMERMANN, 1997; ZWARTJES y HOVDHAUGEN, 2007; CERRÓN-PALOMINO, EZCURRA y ZWARTJES, 2019). Sin embargo, aquí la propuesta es considerar algunos ejemplos de la dinámica de ese recorrido en textos coloniales de diferentes épocas y ambientes geopolíticos de la Colonia. Para hacerlo, partiré de algunas consideraciones generales de 
la lengua española en el momento de la Conquista y de ciertas concepciones doctrinarias que atravesaron la alfabetización de los misioneros. Por último, comentaré algunos textos en los que la problemática de la realidad notipográfica se expone, y en los que se evalúa la literacidad de los nativos americanos y se comentan ciertas prácticas mixtas de voz y corporalidad (los cantos y bailes) que aparecieron como una manifestación inquietante para el proceso de evangelización. Todos estos aspectos implicaron cierto agenciamiento de sujetos, cuerpos y saberes.

\section{La escritura como agenciamiento}

Por un lado, como se ha desarrollado extensamente en diversos trabajos (ASCENCIO, 1960, MIGNOLO, 1992a, 1992b, 1994, 1995; ERRINGTON, 2003; ROJINSKY, 2010; HELLER, 2017), la conquista fue emplazada bajo la obsesión nebrijana de la "lengua compañera del Imperio". El español que llegó a América era ya una lengua estandarizada y gramaticalizada, y por tanto la letra tenía una entidad ontológica superior a la voz. Había, así, una identificación de letra como la voz misma (MIGNOLO, 1992b, p. 189), ya que la entidad material de la escritura desplazó la fuerza de la oralidad en la Modernidad. La fundamentación de Nebrija ante la Corona de la importancia de la estandarización de las lenguas estuvo muy relacionada con la gramática latina de Valla (ASCENCIO, 1960, p. 400-403). Su base filosófico-teológica defendía la posibilidad de alcanzar una lengua capaz de civilizar y cristianizar al mundo, aspirando a ser una lengua unitiva que superara el castigo de Babel, ideas de fuerte calado renacentista basadas en la filosofía neoplatónica, San Agustín y la tradición católica.

Por otro lado, en el orden de la política, si el deseo imperial de España se consideraba equivalente al proyecto del Imperio Romano, y en un juego de espejos providencialista, la Roma católica lograba su amplio desarrollo con la España Imperial, entonces la gramática latina y la gramática del castellano debían ser dos armas invencibles para ordenar, normativizar, establecer los límites, consignar el dominio del territorio. El castellano tomó, así, su lugar de lengua docta y consiguió el estatus para adoctrinar cuerpos y almas, y establecer nuevas administraciones. Así, el poder económico y espiritual de la lengua se hace presente en la conquista bajo la extensión de la gramaticalización. Una lengua estándar, tal como se considera hoy, es un código al que adscribirse, al que pertenecer para establecer vínculos y jerarquías e intercambios (MILROY y MILROY, 2002). Pero a su vez, aquella lengua estandarizada había sido considerada hasta poco tiempo antes como una lengua vernácula relegada de la práctica religiosa, aunque a partir del Concilio de Trento fue entendida como pieza fundamental de la evangelización. El impulso misionero en América, que continuaba la reconquista de la Península, se entendía como 
lucha espiritual, y la misión de la comunicación de la Buena Nueva, como idea ya presente en los Evangelios, se dilata en la imaginación de los cristianos europeos frente a las nuevas tierras de paganos. Esta idea de la comunicación de la religión está vinculada con la idea del Verbo como segunda persona de la Trinidad, el Verbo que era el Logos, el que había creado el mundo y ordenado la realidad. La transmisión de la revelación y el Logos se daba, según los misioneros, en la palabra divina, palabra que se difundiría por el mundo mediante el don de lenguas del Espíritu Santo. Ese don, recibido en Pentecostés, aparece como contrapaso salvífico de la confusión de Babel para la tradición. ${ }^{1}$ De esta manera, el idioma castellano se considera durante la Conquista como una lengua estándar pluricéntrica.

La dominación de la lengua implicaba la denominación de sujetos cuyas corporalidades eran atravesadas por la cultura escrita mediante ordenanzas, leyes, proclamas, bulas (ERRINGTON, 2003, p. 25; ROJINSKI, 2010, p. 223-227). Esto sucedió en pleno furor de la escritura como verificadora de lo verdadero, un principio renacentista de fuerza histórica, filosófica y jurídica que desempeñó un papel formador en la conciencia occidental (CERTEAU, 1990, p. 147-149) como herramienta de dominio de la alteridad. De esta manera, disciplinar cuerpos y conciencias estuvo muy vinculado a introducir las lenguas orales en el cauce no perecedero de lo escrito. Para el conquistador europeo no había otro modo de entender la colonización sino asociada a un concepto de una verdad que tenía base en un plan jerárquico donde un "gran Habla cosmológica" (CERTEAU, 1990, p. 150) -el Logos, el Verbo-"quiere decir" (150) y un auditorio "quiere escuchar" (150). Este concepto de verdad se basa en los principios metafísicos aristotélicos-tomistas para los que se distinguían dos dimensiones de la misma: por un lado, una verdad lógica, como adecuación de la razón a la realidad, y por el otro una verdad ontológica, la adecuación del intelecto al Logos (Santo Tomás de Aquino, ST, I, 16). A partir de estas premisas te(le)ológicas, entre otras, la realidad nueva debía incorporarse al plan de salvación de la cristiandad, porque se consideraba un acto indispensable para la trascendencia. Estos principios hegemónicos debían construirse, por supuesto, bajo la lógica de la religión de la caridad, ya que sugestivamente la «luz de la verdad» debía entrar en el corazón y las inteligencias de los nativos. El modo en que esto se llevó a cabo, como se sabe, atravesó excesos, replanteos y debates que comenzaron con denuncias

1 Esta imagen de la superación del don de lenguas del Espíritu Santo en compensación con el episodio de la Torre de Babel es una idea muy presente en la tradición exegética católica, y está también en el corazón de defensas normativistas de la lengua en autores americanos del siglo XIX, como Caro y Cuervo (recordar el poema "La confusión de lenguas" de Miguel Antonio Caro), y en los debates sobre la lengua en Argentina, atravesados por el concepto de "babelización". Sobre este aspecto de la autoridad, la norma y el concepto de babelización en los debates de diversos autores en América Latina, ver Del Valle (2002), Greußlich (2015), Di Tullio (2003), Ennis (2013; 2019), Oliveto (2016), entre otros. 
explícitas; los documentos de los primeros concilios americanos, la labor de las reducciones, entre otros acontecimientos, pusieron los paradigmas antropológicos en discusión y revisión.

Este procedimiento de asimilación, normativización y regulación se podría considerar un "agenciamiento" (agencement) que tendría la cultura escrita como dispositivo. El agenciamiento como conjunto de relaciones co-funcionales entre elementos heterogéneos (Deleuze y Guattari, 2004) es lo que propone, en definitiva, el concepto del libro: "En un libro, como en cualquier otra cosa, hay líneas de articulación o de segmentaridad, estratos, territorialidades; pero también líneas de fuga" (9-10). Así, en la lógica occidental del libro como objeto donde se suman todos los saberes, en el acto de traducir las nuevas realidades americanas, confluyen dos afirmaciones filosóficas: la teoría de la relación y la composición, el devenir y el deseo (HEREDIA, 2014, p. 94). Esos dos ejes de relación y de deseo, de composición y de movimiento remiten a un ensamblaje de elementos heterogéneos, a una red, a una multiplicidad rizomática (94). Este agenciamiento "no se vincula con ningún tipo de teleología trascendente, sino más bien con el hecho de que los elementos se relacionan en un plano de inmanencia muy concreto y, en él, componen y descomponen, estabilizan y desestructuran determinados sistemas de relaciones" (94-95). Sin embargo, en el caso de la evangelización, este agenciamiento de elementos y su componenda tenían, a su vez, una participación divina y providente.

Esta dinámica pivotea en algunos de los textos del siglo XVI, en los que, en primer lugar, hay una reflexión sobre la entidad de las culturas ágrafas y una consideración sobre el vacío de la letra. Este vacío tomó cuerpo en la preocupación de que no se encontraban en América materiales comparables a los libros de historias, la Biblia o los documentos legales a los que remitirse para entender el sistema de las civilizaciones: la falta de la letra y el libro produjo desconcierto. El agenciamiento fue un acto que se fue ampliando a medida que se develaban las distintas realidades múltiples de las culturas dominadas: símbolos, sonidos, gestos e imágenes debían ser reordenadas como un caos llamado a ser cosmos, pero que debía respetar la ley de semejanza. No sólo la enseñanza del español, sino especialmente la apropiación de las lenguas nativas, implicó para los misioneros un acto de reforma necesaria. Pero, a la vez, también se encargaron de deformarlas

with practices of literacy which let them remove words and meanings from native speech and speakers, before "giving them back" in their own religious discourses, and as symbols of their authority. These intimate and powerful relations could be created and sustained as long as natives' tongues were recognized as necessary but imperfect vessels of Christ's message (ERRINGTON, 2003, p. 45). 
Esas prácticas se revelan en diversos textos coloniales como parte de una conciencia muy temprana sobre el proceso que ya era una estratégica política: controlar las lenguas, asimilar y dirigir aquello que fue considerado intelectualmente inferior, pero que a su vez tenía el poder de ser una fuerza espiritual contraria a la fe.

La alfabetización como agenciamiento: de José de Acosta a Guamán Poma de Ayala.

Uno de los textos que aborda este proceso en el contexto andino es, sin duda, la Historia Natural y Moral de las Indias (1589), de José de Acosta, en donde se da cuenta no sólo de la realidad peruana, sino que también se analizan informes tomados de Mesoamérica. El jesuita tiene, a lo largo de sus textos, una evolución notable en cuanto a la consideración de la capacidad de los indios de aprender los sistemas de escritura europeos y de recibir los principios de la fe. Si en su De Procuranda (1588-89) duda de la civilidad de los indios para entender el evangelio, en la Historia Natural... considera que el nivel intelectual de los indios era suficiente para ser catequizados. La evolución del pensamiento de Acosta es el reflejo de las consideraciones también consignadas en el Tercer Concilio de Lima, en el que se establecen los lineamientos de la evangelización a través del conocimiento y estandarización de las lenguas nativas "generales", es decir, las más habladas de la región. Estos primeros intentos de estandarización suscitaron una serie de catecismos, breviarios y gramáticas en esas lenguas, especialmente después de los concilios limeños (Lisi, 1990).

Para ejemplificar la necesidad de ese ingente esfuerzo, Acosta elabora un informe contrastivo, no sólo entre las culturas peruanas y las mesoamericanas sino también de los procesos escriturarios de China y Japón en donde, por otro lado, ya la acción misionera jesuítica había comenzado. Hay aquí un insistente trabajo de señalamiento de la capacidad cognitiva de los indígenas y se pretende deshacer la falsa opinión que se tenía de los ellos como "gente bruta y bestial y sin entendimiento" (ACOSTA, 2008, p. 395), algo considerado por el sacerdote como un engaño que había sustentado los agravios cometidos contra ellos:

Esta tan perjudicial opinión no veo medio con que pueda mejor deshacerse que con dar a entender el orden y modo de proceder que éstos tenían cuando vivían en su ley: en la cual, aunque tenían muchas cosas de bárbaros y sin fundamento, pero había también otras muchas dignas de admiración, por 
las cuales se deja bien comprender que tienen natural capacidad para ser bien enseñados; y aún, en gran parte, hacen ventaja a muchas de nuestras repúblicas (ACOSTA, 2008, p. 395-396).

Acosta recaba sus propias fuentes indianas para fundamentar sus argumentos: por un lado, se basa en Polo de Ondegardo, historiador del grupo de los "toledanos", y también en Juan de Tovar, que había trabajado arduamente en México junto con amanuenses indígenas para reconstruir una historia occidental de los aztecas. Un apartado de la Historia Natural plantea la consideración antropológica de literacidad de los indígenas en relación a sus sistemas de registro: el capítulo "Que ninguna nación de los indios se ha descubierto que use letras". Acorde con la episteme de su siglo, en la que la semiología y la hermenéutica se superponen en forma de similitud, y en la que la semejanza es el enlace entre el signo y lo que significa (FOUCAULT, 2002, p. 48-49), el jesuita considera que las letras se inventaron para referir y significar inmediatamente las palabras que se pronuncian, ya que "una imagen del sol pintada no se puede decir que es escritura o letras del sol sino pintura, ni más ni menos otras señales que no tienen semejanza con la cosa sino solamente sirven para memoria, porque el que las inventó no las ordenó para significar palabras sino para denotar aquella cosa" (ACOSTA, 2008, p. 205).

Más adelante, cuestionando los principios de los soportes de la memoria, Acosta afirma que la memoria de historias y de la antigüedad puede permanecer en los hombres por letras y escritura, como lo usan los latinos y griegos y hebreos, y otras muchas naciones; por pintura, como casi en todo el mundo se ha usado (206) y, sin embargo, "la pintura es libro para los idiotas que no saben leer" (206). Así, la hipótesis inicial se desarrolla y sostiene a lo largo de estos apartados: "ninguna nación de indios que se ha descubierto en nuestros tiempos usa de letras ni de escritura sino de las otras dos maneras, que son imágenes o figuras; y entiendo esto no sólo de los indios del Perú y de los de Nueva España, sino en parte también de los japonés y chinas" (206). A partir de esta analogía con Oriente, sin embargo, considera necios a los misioneros que, por verlos como hechizos y magia, habían quemado registros y documentos en Yucatán, que no eran otros que los vuh y amoxli, considerados por aquellos cosas de borrachos (208). Con todo, lo distintivo para Acosta es que las figuras y caracteres de los mexicanos no eran tan eficientes como la escritura y letras occidentales, porque éstos no podían concordar puntualmente en las palabras sino solamente referirse a los conceptos. Lo que Acosta (ni Tovar) concebían era el laconismo de estos documentos mesoamericanos, ya que aquellos sólo contenían el esqueleto de una performance, y se esperaba que el intérprete completase los detalles de las inscripciones (MONAGAHAN, 
1994, p. 87). En suma, el texto mixteca además de estar relacionado con la lengua estaba relacionado con el cuerpo del mixteca $(88)^{2}$.

Jerónimo de Oré también hace referencia a la particular característica de la cultura no-tipográfica andina ya que, como el Inca Garcilaso haría más adelante, compara al quechua del Cuzco con lo que fue "el dialecto jónico (...) para Atenas y la lengua latina para Roma” (Andrago Walker 2018: 85). Si bien Oré sostiene que la carencia de método de escritura podía situar a los incas en una escala inferior, asume que el grado de su desarrollo permitiría el acercamiento al cristianismo (85). Tanto él como Acosta refutan además el concepto aristotélico de la zona tórrida que había sido un argumento sostenido para demostrar la incapacidad de comprensión de los nativos. Así, el clima favorecía la capacidad de asimilación de conocimientos y formas escritas: la literacidad de los indios en Acosta y Oré deja de ponerse en duda.

Así como lo hacen Agustín de Zárate y Cieza de León, Oré desarrolla y cuestiona los soportes de la memoria de los incas y los deslegitimiza porque

no hallan razón, ni hallan memoria en las cuentas de sus quipus (...) Tres o cuatro fábulas tienen en diversas provincias, no tan fuera de propósito, que no se infiera en ellas haber tenido fundamento de verdad. Y por los muchos años que han pasado se perdió la verdad, y quedan hasta ahora novelando en su opinión (ANDRAGO-WALKER, 2018, p. 38).

No opina por igual, por su parte, Acosta, que se maravilla de lo sustentable de aquellos soportes de la memoria y menciona especialmente al uso de los dibujos en Mesoamérica para el registro de la conciencia:

Yo vi un manojo de estos hilos, en que una india traía escrita una confesión general de toda su vida y por ellos se confesaba, como yo lo hiciera por papel escrito; y aún pregunté de algunos hilillos que me parecieron algo diferentes, y eran ciertas circunstancias que requería el pecado para confesarle enteramente (ACOSTA, 2008, p. 210).

La intervención en los dispositivos de memoria era similar en los diseños geométricos de los keros, donde las figuras representaban clases genéricas de incidentes que luego el intérprete especificaba (RAPPAPORT, 1994, p. 284). Esta práctica, por otro lado, también se ejecutó a la inversa en muchos casos, como los indígenas andinos que interpretaban de igual manera las letras escritas. Los signos en líneas ordenadas de la escritura occidental eran

2 Con todo, y haciendo referencia a una práctica habitual en la catequética franciscana en Mesoamérica, Acosta rescata cómo algunos nativos, para recordar la oración de la confesión, pintaban una figura de indio hincado de rodillas a los pies de un religioso y escribían toda la confesión por imágenes, lo cual demostraba, para el sacerdote, la viveza y el ingenio de estas civilizaciones. 
entendidos por los indígenas como signos abstractos cuyo significado debía decodificar el especialista. ${ }^{3}$ La mnemotecnia como práctica y dispositivo fue paulatinamente desplazada por los conquistados, probablemente no porque éstos consideraran a la letra como sistema superior, sino porque hubo una sumisión necesaria a la ideología legal, nacida en la dominación colonial y traída del occidente escriturario ${ }^{4}$.

La imaginería en diálogo con el texto, por su parte, está en la estructura y la concepción de Guamán Poma de Ayala en su Primera nueva corónica y buen gobierno en que se combinan las lenguas y los métodos. A partir de los soportes orales y la información atribuida a los quipus, entabla un relato de la historia mediante la escritura y el dibujo, considerando a estos no meros accesorios sino otro modo en paralelo de estructurar la narración (ADORNO, 2001). Las referencias al método de composición es declarado en la introducción de la corónica en el "prólogo al lector cristiano" asumiendo la voz de un indio converso y activando una retórica funcional a la corona:

viendo la ocasión en las manos el escrito, para sacar en limpio estas dichas historias hube tanto trabajo por ser sin escrito ni letra alguna, sino no más de quipos [cordeles con nudos] y relaciones de muchas lenguajes ajuntando con la lengua de la castellana y quichiua ynga, aymara, poquina colla, canche, cana, charca, chinchaysuyo, andesuyo, collasuyo, condesuyo, todos los vocablos de indios, que pasé tanto trabajo por ser servicio de Dios Nuestro Señor y de su Sacra Católica Magestad, rey don Phelipe el tercero. (POMA DE AYALA, I, 1980, p. 11).

Tardíamente descubierto y extensamente señalado por la "imprecisión" de los datos que aportara y la dudosa gramática de su español (ADORNO, 2000, p. 5), Poma de Ayala manifiesta en su trabajo una evidencia, en muchos de niveles, del agenciamiento de la escrituralidad en los sistemas de representación del incario. Los saberes no-tipográficos irrumpen en el espacio de la decodificación de la información y allí emerge, y de manera especial en los dibujos, una amalgama de letras, lenguas, figuras y vestimentas. Las inscripciones aparecen como glosas explicativas, en quechua y español, a veces como exhaladas de la boca de los personajes, y otras veces inscriptas en las pieles de animales y en los miembros. Esas inscripciones coexisten con otras: las figuras geométricas de los vestidos con las que se representan dioses

3 Es el caso de aquel indio que fue apresado y que apelaba a una carta escrita por Dios de que esa orden era incorrecta. Cuando le pidieron que mostrara la carta, el indio les extendió un papel en blanco. Los soldados le preguntaron dónde estaba la escritura de Dios en esa hoja, el indio les mostró la marca de imprenta del papel. (RAPPAPORT, 1994, p. 285)

4 Para una aproximación sobre las lenguas indígenas, los intérpretes y el sistema legal en América Latina desde la colonia, ver Cunill/Glave Testino (2019). 
y reyes incas. La Corónica, de todos modos, insiste en que la Conquista era un proceso político y espiritual necesario para cumplir ese plan de salvación. Así lo deja ver en una de las primeras imágenes donde el Espíritu Santo le dicta a Martín de Ayala la información que debía transcribir el letrado. Como sostiene en otra apuntación, los dibujos del texto estaban orientadas a "aquellos que no leen" (POMA DE AYALA, 1980, I, p. 9), mientras que la letra estaba dirigida "para aquellos que saben leer" (POMA DE AYALA, 1980, I, p. 9). Pero la composición de los cuadernillos muestra la supremacía de los dibujos sobre el texto.

En su relato, así como el panteón inca y el cristiano están en igualdad de condiciones de dignidad, los idiomas generales del Perú, el quechua y el aymara, tienen también una jerarquía paralela, aunque haya anotaciones críticas de las costumbres paganas de unos y los abusos de otros. Con todo, la memoria del pasado inca era capaz de tomar cuerpo en el género y forma de la historia occidental: el libro, como agenciamiento de la realidad, lo vuelve a hacer posible, pero otros planes de significación se despliegan, donde la corporalidad y la voz tienen una residencia específica.

Tomar la lengua, poseer el cuerpo: voces y bailes

Para Mignolo (1994), la colonización de Occidente de culturas tipográficas (en las que la lengua se plantean como extensión de las manos) fue más exitosa que la colonización de las lenguas orales americanas, porque estas estaban inscriptas en el cuerpo (314). Las lenguas orales implicaban un continuum de creencias, voces, rituales y movimientos, experiencias de difícil demarcación y asimilación. No obstante, en la vía metodológica de la semejanza como categoría ordenadora, se llegaron a considerar cierta similitud gramatical entre lenguas europeas y americanas y por lo tanto, casi en igualdad de importancia, como señala en la carta prólogo del Grammatica o arte de la lengua general del Perú (1560), de Domingo de Santo Tomas, quien resaltaba

la gran policia que esta lengua tiene, la abundancia de vocablos, la conveniencia que tienen con las cosas que significan. Las maneras diversas y curiosas de hablar. El suave y buen sonido al oydo de la pronunciación della, la facilitad para escrivirse con nuestros caracteres y letras: quanfacil y dulce sea a la pronunciacion de nuestra lengua, el estar ordenada y adornada con propiedad de declinacion, y demas propiedades del nombre, modos, tiempos, y personas del verbo. Y brevemente en muchas cosas y maneras de hablar, tan conforme a la latina, y española: y en el Arte y artificio della, que no paresce sino que fue un pronostico, que Españoles la auian de poseer (Santo Tomás de Aquino, 1560, vi). 
La factibilidad de estandarizar al quechua era, de esta manera, una señal de su predestinada posesión, pronóstico hecho a partir de su vínculo de semejanza, ya que poseer y sujetar la lengua mediante la gramática era incluir a los hablantes en la dimensión salvífica y en la subordinación.

Esta idea de posesión de cuerpos y lenguas tuvo, por otro lado, una dimensión incómoda para el proceso de agenciamiento: el canto y la danza de los indígenas. El baile fue de las costumbres de los indígenas que más resistencia causó entre los españoles. En toda América Latina la danza y el canto eran formas de oración, considerados actos distinguibles para un europeo. La oración involucraba el lenguaje, mientras que la danza involucraba el movimiento de todo el cuerpo (MONAHAGAN, 1994, p. 90) y, de esta forma, completaba también los significados de las voces. De nuevo aquí vale poner de ejemplo los códices mixtecas que no solamente precisaban de un intérprete. Su dimensión performática no se reducía a presentaciones verbales de cantos y canciones, sino que allí se daba voz a través de todo el cuerpo: de la coreografía, de los gestos, de la ropa que usaban, de las expresiones, lo verbal y lo no verbal (91).

José Acosta describe así el fenómeno en distintos pueblos de América:

Destas danzas la mayor parte era superstición y género de idolatría, porque así veneraban sus ídolos y guacas. Por lo cual han procurado los prelados evitarles lo más que pueden semejantes danzas, aunque -por ser mucha parte de la pura recreación- les dejan que todavía dancen y bailen a su modo.

Tañen diversos instrumentos para estas danzas: unas como flautillas o cañutillos, otros como atambores, otros como caracoles; lo más ordinario es en voz cantar todos, yendo uno o dos diciendo sus poesías, y acudiendo los demás a responder con el pie de la copla. Algunos destos romances eran muy artificiosos y contenían historia, otros eran llenos de superstición, otros eran puros disparates (ACOSTA, 2008, p. 227).

La lengua corporizada en el baile es, así, por un lado rechazada para la catequética, por ser un tipo de movimiento incompatible con la liturgia. Pero aquellas voces tomadas del continuum de los cantos son también apropiadas y modificadas, traduciendo e introduciendo los nombres cristianos en reemplazo de los de sus divinidades, como atestigua uno de los primeros documentos sobre la conquista de la zona guaraní. El guaraní, lengua general tardíamente estandarizada, fue de las más uniformes de América a pesar de su extensión. Los tupiguaraníes no tuvieron soportes de registros conocidos, ni imágenes ni códigos de comunicación, como señala Martín del Barco Centenera en su poema Argentina y conquista del Río de la Plata (1602). Éste es uno de los primeros documentos sobre la región que da cuenta de léxico en guaraní, y en 
el cual se proponen etimologías. Pero aquí también aparecen descripciones de sus cantos y bailes, y de un consciente sistema de catequización que disponía apropiarse de matrices culturales para la causa evangelizadora:

Entre otros cantares que les hacía cantar, el más celebrado y ordinario, según alcancé a saber, era éste: Obera, obera, obera, paytupa, yandebe, hiye, hiye, hiye, que quiere decir: «Resplandor, resplandor del padre, también dios a nosotros, holguémonos, holguémonos, holguémonos». Y yo les hice entrometiesen entre aquellas dos palabras paytupa y la otra yandebe, que quiere decir «también el dulce nombre de Jesús», por manera que de allí adelante cantaban así: Obera, obera, paytupa Jesus, yandebe, hiye, hiye, hiye. (BARCO CENTENERA, 1998, p. 295)

El evangelizador "entromete", "hace decir", en su propia lengua, un mensaje adecuado a los fines catequísticos, pero también, es un modo de ejercer esa inscripción lingüística en lo oral y lo corporal, una dominación mediada por la corrupción del canto original. La misma práctica declara Acosta que se hacía con los indígenas del Perú:

Los nuestros que andan entre ellos han probado ponelles las cosas de nuestra santa fe en su modo de canto, y es cosa grande el provecho que se halla: porque con el gusto del canto y tonada cantan días enteros, oyendo y repitiendo sin cansarse. También han puesto en su lengua composiciones y tonadas nuestras - como de octavas y canciones de romances, de redondillas- y es maravilla cuán bien las toman los indios. (ACOSTA, 2008, p. 227)

Aquel "lovingly destructive projects of conversion", como lo llama Errington (2003, p. 23), también se basó en la posesión de las lenguas paganas: lenguas apropiadas, adaptadas y removidas con el fin de reemplazar, de este modo, los paganos modos de vida (20).

En suma, el paulatino proceso de occidentalización de América Latina implicó nuevos sujetos en disposición de un nuevo orden basado en un derecho que, en palabras de Certeau (1990):

se apropia de los cuerpos para hacerlos su textos. (...) Estas escrituras efectúan dos operaciones complementarias: para estas escrituras, los seres vivos son, por un lado, "puestos en texto", transformados en significantes de reglas (se trata de una intextuación) y, por otro, la razón o el Logos de una sociedad "se hace carne" (se trata de una encamación). (153)

Estas dos operaciones también estuvieron presentes durante la Conquista: los nativos americanos fueron puestos en textos, como en los textos que se han comentado. En esa instauración de la legalidad, también 
se buscó encarnar el Verbo, el Logos ordenador de la cristiandad, a través de una lengua pluricéntrica como el español, una lengua litúrgica como el latín y de la gramaticalización de las lenguas indígenas. Por su parte, los sistemas de escrituras no tipográficas entablaron su propia batalla, desde el agenciamiento de la propia voz mediante el sistema de escritura europeo, como en el caso de Guamán Poma, hasta el proceso administrativo en el cual la letra era soporte, y mediante la cual debían establecerse las jerarquías y el dominio de cuerpos y territorios.

Así pues, el agenciamiento, como componenda o ensamblaje funcionó en la asimilación de la realidad americana por parte de los letrados europeos. Éste tuvo durante la Conquista una impronta doble: por un lado, había que atender a una realidad material, había que imponer el sistema imperial, pero al mismo tiempo, era perentorio traducir, interpretar, comprender en categorías occidentales objetos y movimientos de distintas culturas. Este ensamblaje, en el plano ideológico, no fue meramente material sino que tuvo una impronta trascendental para el evangelizador que veía como imprescindible hacer entrar en la historia de la religión cristiana a esos individuos que tenían que estar incluidos en ella.

\section{Referencias}

ACOSTA, José de. Historia natural y moral de las Indias. (F. d. Díaz, Ed.) Madrid: Consejo Superior de Investigaciones Científicas, 2008.

ADORNO, Rolena. Contenidos y contradiccionesla obra de Felipe Guaman Poma y las aseveraciones acerca de Blas Valera. CiberLetras: revista de crítica literaria y de cultura, n. 2, 2000.

ADORNO, Rolena. Guaman Poma and his illustrated chronicle from colonial Peru: from a century of scholarship to a new era of reading. Copenhagen: Museum Tusculanum Press, University of Copenhagen \& the Royal Library, 2001.

ASCENCIO, Eugenio. La lengua compañera del imperio. Historia de una idea de Nebreija en España y Portugal. Revista de Filología Española, v. XLIII, n. 3/4), 1960 , p. 390-413.

LA BIBLIA DE JERUSALÉN. Bilbao: Desclées des Brouwer, 1998.

CERRÓN-PALOMINO, R.; EZCURRA, A.; Zwartjes, O. Lingüistica misionera Aspectos lingüisticos, discursivos, filológicos y pedagógicos. Lima: Fondo Editorial, 2019. 
CERTEAU, Michel de. La invencion de lo cotidiano. Trad. Alejandro Pescador. Ciudad de México: Universidad Iberoamericana, 1990.

CUNILL, C.; GLAVE TESTINO, L. M. Las lenguas indigenas en los tribunales de América Latina: interpretación, mediación y justicia (siglos XVI-XXI). Bogotá: Instituto colombiano de antropología e historia, 2019.

DEL VALLE, José. "Historical linguistics and cultural history: The polemic between Rufino José Cuervo and Juan Valera". In: DEL VALLE, José, GABRIELSTHEEMAN, Luis (eds.). The Battle over Spanish between 1800 and 2000. Language Ideologies and Hispanic Intellectuals. London/New York: Routledge, 2002, p. 64-77.

DERRIDA, Jacques. Mal de archivo. Una impresión freudiana. Madrid: Trotta, 1997.

ENNIS, Juan Antonio. Miguel Antonio Caro, la lengua y la ley. RASAL Lingüistica, 2013, p. 27-39.

ENNIS, Juan Antonio. "Language, politics and secularization: Language-ideological debates in the Latin American Press in the 1870s". In: Marimón Llorca, Carmen; Schwarze, Sabine (eds.). Authoritative discourse in language columns: linguistic, ideological and social issues. Frankfurt: Peter Lang, 2019.

ERRINGTON, Joseph. Linguistics in a Colonial World. A Story of Languaje. Oxford/ Malden MA: Blackwell, 2003.

FOUCAULT, Michel. Las palabras y las cosas. Una arqueología de las ciencias humanas. México: Siglo XXI, 2002.

GREUßLICH, Sebastian. El pluricentrismo de la cultura lingüística hispánica: política lingüística, los estándares regionales y la cuestión de su codificación. Lexis, v. XXXIX, n. 1, 2015, p. 57-99.

GRUZINSKI, Serge. La colonización de lo imaginario. Sociedades indígenas y occidentalización en el México español. Siglo XVI-XVIII. México: Fondo de Cultura Económica, 2006.

HEREDIA, Juan Manuel. Dispositivos y/o Agenciamientos. Contrastes. Revista Internacional de Filosofía, v. XIX, n. 1, 2014, p. 83-101.

HELLER, M., \& MCELHINNY, B. Language, capitalism, colonialism. Toronto: University of Toronto Press, 2018.

HOVDHAUGEN, Even. "Missionary Grammars. An Attempt at Defining a Field of Research". In: ... and the Word was God. Missionary Linguistics and Missionary Grammar. Hovdhaugen, Even (ed.). Münster: Nodus, 1996, p. 9-22. 
MIGNOLO, Walter. Nebrija in the New World: The Question of the Letter, the Colonization of Amerindian Languages, and the Discontinuity of the Classical Tradition. L'Homme, n. 122/124, 1992.

MILROY, J.; MILROY, L. Authority in Language. Investigating Standard English. London: Routledge, 2002.

MONAGAHAN, John. The text in the body, the body in the text. The embodied sign in mixtec writing. In: BOONE, Elizabeth Hill; MIGNOLO, Walter (eds.). Writing Without Words: Alternative Literacies in Mesoamerica and the Andes. Durham, NC: Duke University Press, 1994.

POMA DE AYALA, Guamán. Nueva corónica y buen gobierno. V. I. Caracas: Biblioteca de Ayacucho, 1980.

ROJINSKY, David. Companion to Empire. A Genealogy of the Written Word in Spain and New Spain (c. 550-1550). Amsterdam: Rodopi, 2010.

SANTO TOMAS, Domingo de. Grammatica o arte de la lengua general de los indios de los reynos del Peru. Valladolid: Francisco Fernández de Córdova, 1560.

ZWARTJES, O.; HOVDHAUGEN, E. (eds.) Missionary Linguistics/Lingüística misionera. Selected papers from the first International Conference on Missionary Linguistics. Oslo, 13-16 march 2003. Amsterdam \& Philadelphia: John Benjamins, 2004 .

Eugenia Ortiz Gambetta. Profesora adjunta de Literatura Argentina I en la Universidad Católica Argentina y becaria posdoctoral ANPCyT-Universidad Nacional de La Plata (Argentina). Sus trabajos se han centrado en los discursos coloniales latinoamericanos y del siglo XIX. Sus temas de interés son, entre otros, las problemáticas entorno a las prácticas filológicas latinoamericanas, el archivo colonial y la articulación entre discursos políticos y ficcionales. Junto con Javier de Navascués preparó la edición crítica del poema épico colonial Argentina y conquista del Río de la Plata (1602), de Martín del Barco Centenera, que será publicada por Iberoamericana/Vervuert en 2020. E-mail: mariaeugeniaortiz@uca.edu.ar 